\title{
Aeromonas taiwanensis sp. nov. and Aeromonas sanarellii sp. nov., clinical species from Taiwan
}

Correspondence
Maria J. Figueras
mariajose.figueras@urv.cat

\author{
Anabel Alperi, ${ }^{1}$ Antonio J. Martínez-Murcia, ${ }^{2}$ Wen-Chien Ko, ${ }^{3}$ \\ Arturo Monera, ${ }^{2}$ Maria J. Saavedra ${ }^{2,4}$ and Maria J. Figueras ${ }^{1}$
${ }^{1}$ Unit of Microbiology, Rovira i Virgili University, IISPV, Sant Llorenç 21, 43201 Reus, Spain
${ }^{2}$ Molecular Diagnostics Center (MDC), Biomolecular Technologies SL, and Miguel Hernández University, 03300 Orihuela (Alicante), Spain
${ }^{3}$ Department of Medicine, National Cheng Kung University, Tainan, Taiwan ROC
${ }^{4}$ Department of Veterinary Sciences, CECAV - University of Trás-os-Montes e Alto Douro, Vila Real, Portugal

\begin{abstract}
Two clinical Aeromonas strains $\left(\mathrm{A} 2-50^{\top}\right.$ and $\left.\mathrm{A} 2-67^{\top}\right)$ recovered from the wounds of two patients in Taiwan could not be assigned to any known species of this genus based on their 16S rRNA gene sequences, which showed similarities of $99.6-99.8 \%$ to those of the type strains of Aeromonas caviae, $A$. trota and $A$. aquariorum. The $r p o D$ phylogenetic tree allocated these strains to two novel and independent phylogenetic lines, the neighbouring species being $A$. caviae, the type strain of which showed $93.2 \%$ similarity (56 bp differences) to strain $\mathrm{A}_{2}-50^{\top}$ and $92.2 \%$ (63 bp differences) to strain $\mathrm{A} 2-67^{\top}$. A multilocus phylogenetic analysis of five housekeeping genes $(g y r B, r p o D, r e c A, d n a J$ and $g y r A ; 3684 \mathrm{bp})$ confirmed that the two strains formed independent phylogenetic lineages within the genus. These data, together with phenotypic characterization and DNA-DNA reassociation results, revealed that these strains represent novel Aeromonas species, for which the names Aeromonas taiwanensis sp. nov. (type strain A2-50 ${ }^{\top}$ $=$ CECT $7403^{\top}=$ LMG $24683^{\top}$ ) and Aeromonas sanarellii sp. nov. (type strain A2-67 ${ }^{\top}=$ CECT $7402^{\top}=$ LMG $24682^{\top}$ ) are proposed.
\end{abstract}

The genus Aeromonas includes facultatively anaerobic, Gramnegative, non-spore-forming bacilli or coccobacilli that are generally motile, usually oxidase- and catalase-positive, able to reduce nitrate to nitrite and generally resistant to the vibriostatic agent $\mathrm{O} / 129$ (2,4-diamino-6,7-diisopropylpteridine) (Abbott et al., 2003; Martin-Carnahan \& Joseph, 2005). The genus belongs to the family Aeromonadaceae, order Aeromonadales, class Gammaproteobacteria (MartinCarnahan \& Joseph, 2005). At the time of writing, the genus Aeromonas includes 20 recognized species: Aeromonas hydrophila (the type species), A. bestiarum, A. salmonicida, A. caviae, A. media, A. eucrenophila, A. sobria, A. veronii, A. jandaei, A. schubertii, A. trota, A. allosaccharophila, A.

Abbreviation: MLPA, multilocus phylogenetic analysis.

The GenBank/EMBL/DDBJ accession numbers for the 16S rRNA, gyr $B, r p o D$, rec $A$, dnaJ and gyrA gene sequences of strains $A 2-50^{\top}$ and A2-67 ${ }^{\top}$ are respectively FJ230077 and FJ230076, FJ807272 and FJ807277, FJ472928 and FJ472929, FJ472930 and FJ47931, FJ807270 and FJ807279 and FJ807274 and FJ807276.

An unrooted 16S rRNA gene sequence-based maximum-parsimony phylogenetic tree, an unrooted MLPA minimum-evolution tree, details of differences in the 16S rRNA gene sequences of the novel strains and DNA-DNA hybridization results are available as supplementary material with the online version of this paper. encheleia, A. popoffii (Martin-Carnahan \& Joseph, 2005), A. simiae (Harf-Monteil et al., 2004), A. molluscorum (MiñanaGalbis et al., 2004), A. bivalvium (Miñana-Galbis et al., 2007), A. aquariorum (Martínez-Murcia et al., 2008), A. tecta (Demarta et al., 2008) and the recently described A. fluvialis, isolated from river water (Alperi et al., 2010). Furthermore, Aeromonas piscicola, isolated from diseased fish, has been proposed by our group (Beaz-Hidalgo et al., 2009), as well as some reclassifications (Martínez-Murcia et al., 2007, 2009). The taxonomy of this genus is complex because, despite each species apparently having specific phenotypic characteristics, biochemical identification is laborious and very imprecise, showing poor correlation with genotypic identification (Borrell et al., 1998; Soler et al., 2003; Figueras, 2005; Ormen et al., 2005). The 16S rRNA gene sequence similarity among species of the genus is very high, ranging from 96.7 to $100 \%$ (Martínez-Murcia et al., 1992, 2007; Saavedra et al., 2006). Furthermore, this gene presents microheterogeneities (Figueras et al., 2005; Martínez-Murcia et al., 2005; Morandi et al., 2005; Alperi et al., 2008) that reduce its usefulness for identification (Alperi et al., 2008); such was the case for Aeromonas culicicola (Figueras et al., 2005; Alperi et al., 2008), now considered a synonym of $A$. veronii (Huys et al., 2005). However, several housekeeping genes have proven to have 
high discriminatory power for differentiating neighbouring species and have been used to clarify the phylogeny of Aeromonas (Yañez et al., 2003; Soler et al., 2004; Küpfer et al., 2006; Nhung et al., 2007; Sepe et al., 2008).

Aeromonas strains are primarily inhabitants of aquatic environments, often associated with fish and human diseases (Figueras, 2005; Martin-Carnahan \& Joseph, 2005). The most common clinical presentation of Aeromonas is diarrhoea, followed by localized soft-tissue infections and bacteraemia, the prevailing associated species being A. veronii, A. caviae and A. hydrophila (Figueras, 2005). In recent years, numerous cases of Aeromonas infection have been described in Taiwan (Huang et al., 2007; Wu et al., 2007 and references therein). The present investigation was initiated to identify genetically a group of extraintestinal Aeromonas strains isolated in the National Cheng Kung University Hospital (Tainan, Taiwan) using a previously described 16S rRNA gene RFLP method (Figueras et al., 2000). Two of these strains, $\mathrm{A} 2-50^{\mathrm{T}}$ and A2-67 ${ }^{\mathrm{T}}$, received as A. hydrophila and A. caviae, respectively, showed atypical RFLP patterns similar to patterns observed for A. caviae strains that presented microheterogeneities in the $16 \mathrm{~S}$ rRNA gene (Alperi et al., 2008). However, the $r p o D$ sequences showed that these strains might constitute novel and independent phylogenetic lines within Aeromonas.

In the present study, a polyphasic approach, based on $16 \mathrm{~S}$ rRNA gene sequence analysis, multilocus phylogenetic analysis (MLPA) of five genes ( $g y r B, r p o D, r e c A, d n a J$ and gyrA), DNA-DNA reassociation experiments and phenotypic analysis, was adopted to establish the taxonomic position of the clinical isolates $\mathrm{A} 2-50^{\mathrm{T}}$ and $\mathrm{A} 2-67^{\mathrm{T}}$.

Strain $\mathrm{A} 2-50^{\mathrm{T}}$, together with strains of Enterobacter cloacae and Enterococcus sp., was isolated on the tenth day of hospitalization from a burn wound of a 40 -year-old male with flame burns involving $52 \%$ of the body surface area. The patient also developed a concurrent Aeromonas and Enterococcus bacteraemia, but unfortunately the Aeromonas blood isolate was lost. Both the burn wound infection and the bacteraemia were considered nosocomial. Strain A2$67^{\mathrm{T}}$ was isolated from a 70 -year-old female with noninsulin-dependent diabetes mellitus. She had experienced trauma and had abrasion wounds over her right elbow and a right humeral fracture. On admission, a wound culture from her right elbow grew Aeromonas, Pseudomonas aeruginosa and Bacillus species. No bacteraemia was noted.

To perform the phylogenetic study, strains $\mathrm{A} 2-50^{\mathrm{T}}$ and $\mathrm{A} 2-$ $67^{\mathrm{T}}$ were cultured on sheep-blood agar at $30{ }^{\circ} \mathrm{C}$ and DNA was extracted from single colonies using InstaGene Matrix (Bio-Rad) following the manufacturer's instructions in order to sequence the $16 \mathrm{~S}$ rRNA (1503 bp) and rpoD (820 bp) genes. Primers and conditions for amplification and sequencing have been described previously (MartínezMurcia et al., 1992; Soler et al., 2004).

The MLPA was performed on the basis of $\operatorname{gyrB}(923 \mathrm{bp}$ ), $r p o D$ (652 bp), recA (600 bp), dnaJ (800 bp) and gyrA
(709 bp) gene sequences, as described elsewhere (A. J. Martínez-Murcia, A. Monera, R. Oncina, M. Lopez-Alvarez, E. Lara, M. J. Saavedra \& M. J. Figueras, unpublished results).

The sequences obtained were aligned with the sequences of type and references strains of all members of the genus Aeromonas that were available in GenBank (http://www. ncbi.nlm.nih.gov/sites/entrez? $\mathrm{db}=$ nuccore) by using the CLUSTAL W program, version 1.83 (Thompson et al., 1994). Genetic distances and clustering were obtained using Kimura's two-parameter model (Kimura, 1980) and phylogenetic trees were reconstructed by the neighbourjoining, maximum-parsimony and minimum-evolution methods (Saitou \& Nei, 1987) using the MEGA4 program (Tamura et al., 2007). Stability of relationships was assessed by bootstrapping (1000 replicates).

16S rRNA gene phylogenetic trees (Fig. 1 and Supplementary Fig. S1, available in IJSEM Online) showed strains $\mathrm{A} 2-50^{\mathrm{T}}$ and $\mathrm{A} 2-67^{\mathrm{T}}$ as independent phylogenetic lines within the genus Aeromonas. The strains clustered in the $16 \mathrm{~S}$ rRNA gene trees with $A$. caviae, A. trota and $A$. aquariorum, with robust bootstrap values of $99 \%$ when the phylogeny was inferred with the neighbour-joining algorithm (Fig. 1) and $96 \%$ with the maximum-parsimony algorithm (Supplementary Fig. S1). The two strains were highly related to each other, with just three bp differences $(99.8 \%)$ between their 16S rRNA gene sequences. The nearest type strains to strains $\mathrm{A} 2-50^{\mathrm{T}}$ and $\mathrm{A} 2-67^{\mathrm{T}}$ on the basis of the 16S rRNA gene sequence were those of $A$. trota (99.7 and $99.6 \%$ similarity, four and five bp differences, respectively), A. caviae ( 99.6 and $99.7 \%$ similarity, five and four bp differences) and the recently described A. aquariorum (99.8 and $99.6 \%$ similarity, two and five bp differences). Chromatogram analysis of the 16S rRNA gene sequences (1503 bp) of strains $A 2-50^{\mathrm{T}}$ and $\mathrm{A} 2-67^{\mathrm{T}}$ revealed the existence of microheterogeneities in eight and three positions, respectively (Supplementary Table S1), representing variability of $0.53 \%$ and $0.2 \%$, respectively. Microheterogeneities were located within the V3 and V6 regions, which contain signature nucleotides that enable identification of most Aeromonas species (Martínez-Murcia et al., 1992; Saavedra et al., 2006), thereby hampering proper identification (Alperi et al., 2008). Strains A2-50 and $\mathrm{A} 2-67^{\mathrm{T}}$ showed $99 \%$ similarity to the type strains of $A$. caviae, A. trota and A. aquariorum using BLAST (http://blast. ncbi.nlm.nih.gov/Blast.cgi). This high similarity is in agreement with generally observed similarity within this genus. In fact, two type strains, those of A. salmonicida and A. bestiarum, possess identical 16S rRNA gene sequences (Martínez-Murcia et al., 1992, 2005), and the other type strains possess similarities that range from $96.8 \%$ (48 bp differences between $A$. simiae and A. bestiarum) to $99.8 \%$ (three bp differences between $A$. molluscorum and $A$. encheleia and between A. hydrophila and A. media). Consequently, the 16S rRNA gene sequence similarity cut-off value of $97 \%$ proposed for species differentiation (Stackebrandt \& Goebel, 1994; Stackebrandt et al., 2002) 


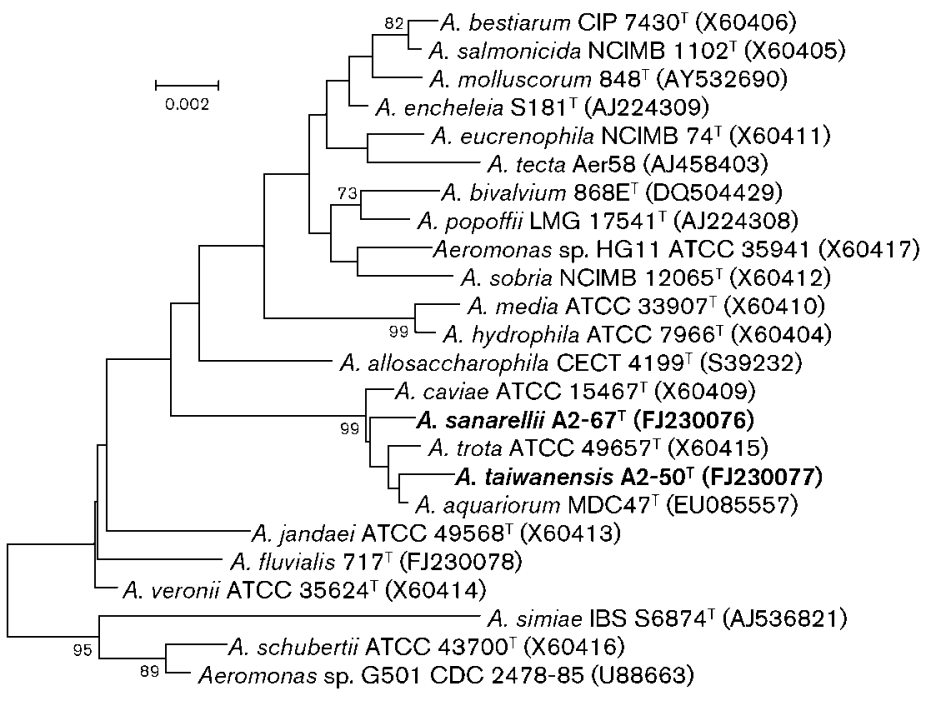

Fig. 1. Unrooted neighbour-joining phylogenetic tree derived from 16S rRNA gene sequences $(1503 \mathrm{nt})$ showing the relationships of strains $\mathrm{A} 2-50^{\top}$ (Aeromonas taiwanensis sp. nov.) and $\mathrm{A} 2-67^{\top}$ (Aeromonas sanarellii sp. nov.) to currently known species of Aeromonas. Numbers at nodes indicate bootstrap values (percentages of 1000 replicates). Bar, 0.002 substitutions per nucleotide position. cannot be applied to Aeromonas, nor can the new proposed value of $98.7-99 \%$ (Stackebrandt \& Ebers, 2006). This statement agrees with conclusions derived from an early 16S rRNA gene sequence phylogeny published by Martínez-Murcia et al. (1992), where absolute values for species delineation in bacteria were not recommended because of different rates of sequence divergence.

The rpoD phylogenetic tree showed strains $\mathrm{A} 2-50^{\mathrm{T}}$ and $\mathrm{A} 2-$ $67^{\mathrm{T}}$ as two independent phylogenetic lines within Aeromonas (Fig. 2), showing $92.7 \%$ similarity (59 bp differences) between their sequences. The nearest type strain on the basis of the rpoD gene was that of A. caviae, showing sequence similarities of $93.2 \%$ (56 bp differences) to $\mathrm{A} 2-50^{\mathrm{T}}$ and $92.2 \%$ (63 bp differences) to $\mathrm{A} 2-67^{\mathrm{T}}$. These values are below the mean intraspecies similarity of $97 \%$ established previously for the $r p o D$ gene in the genus Aeromonas (Soler et al., 2004) and confirmed in our laboratory after sequencing this gene in more than 149 strains of different species (not shown).
The MLPA tree showed, in concordance with the $r p o D$ phylogeny and in contrast to the $16 \mathrm{~S}$ rRNA gene, that strains $\mathrm{A} 2-50^{\mathrm{T}}$ and $\mathrm{A} 2-67^{\mathrm{T}}$ were not phylogenetically related to $A$. trota or A. aquariorum (Fig. 3 and Supplementary Fig. S2), but appeared in the same cluster that included A. media and A. caviae, forming independent branches. Species delineation based on the analysis of five housekeeping genes has been recommended (Stackebrandt et al., 2002), although only the recently described A. fluvialis (Alperi et al., 2010) and the two species described in this study comply with this recommendation in the genus Aeromonas.

To establish DNA-DNA reassociation values, DNA was extracted using Marmur's method (Marmur, 1961). Reassociation experiments were conducted using the methodology of Ziemke et al. (1998) and Urdiain et al. (2008). Reassociation was performed under optimal conditions at $70{ }^{\circ} \mathrm{C}$, reassociation values were determined at least three times (direct and reciprocal reactions, e.g. $\mathrm{A} \times \mathrm{B}$ and $\mathrm{B} \times \mathrm{A}$ ) for any given strain pair and results are

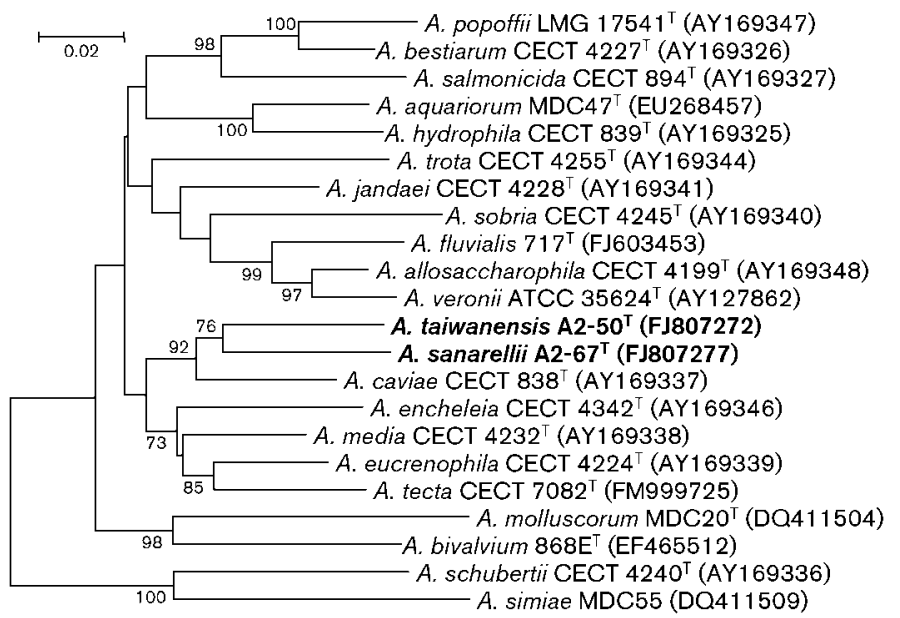

Fig. 2. Unrooted neighbour-joining phylogenetic tree derived from $r p o D$ gene sequences $(720 \mathrm{nt})$ showing the relationships of strains $\mathrm{A} 2-50^{\top}$ (A. taiwanensis sp. nov.) and $\mathrm{A} 2-67^{\top}$ (A. sanarellii sp. nov.) to currently known species of Aeromonas. Numbers at nodes indicate bootstrap values (percentages of 1000 replicates). Bar, 0.02 substitutions per nucleotide position. 


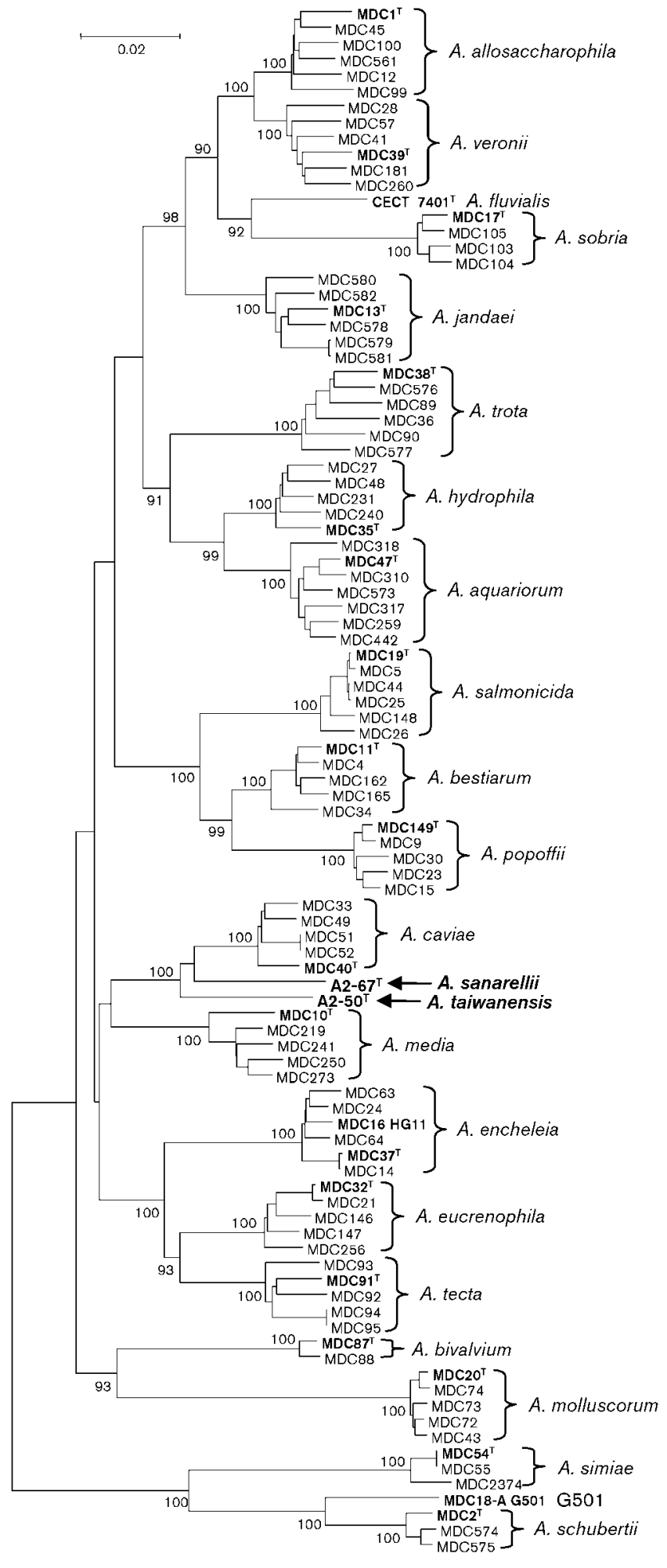

Fig. 3. Unrooted neighbour-joining phylogenetic tree derived from MLPA ( $g y r B, r p o D, r e c A$, dnaJ and $g y r A$ ) showing the relationships of strains $\mathrm{A} 2-50^{\top}$ ( $A$. taiwanensis sp. nov.) and $\mathrm{A} 2-67^{\top}$ ( $A$. sanarellii sp. nov.) to currently known species of Aeromonas. The phylogenetic tree was constructed with a concatenated sequence of 3684 nt. Numbers at nodes indicate bootstrap values (percentages of 1000 replicates). Bar, 0.02 substitutions per nucleotide position. expressed as means $\pm \mathrm{SD}$, as described previously (Alperi et al., 2010). The mean DNA-DNA reassociation values between strains $\mathrm{A} 2-50^{\mathrm{T}}$ and $\mathrm{A} 2-67^{\mathrm{T}}$ and A. caviae CECT $838^{\mathrm{T}}$ and A. media CECT $4232^{\mathrm{T}}$, the most closely related type strains on the basis of MLPA, were 59.9 and $64.7 \%$, respectively, with $A$. caviae CECT $838^{\mathrm{T}}$ and 54.5 and $29.4 \%$, respectively, with $A$. media CECT $4232^{\mathrm{T}}$; the two novel strains showed $63.8 \%$ relatedness (Supplementary Table S2). These values were all below the $70 \%$ established for species delineation (Wayne et al., 1987; Stackebrandt \& Goebel, 1994; Stackebrandt et al., 2002; Rosselló-Móra, 2006). Although DNA-DNA hybridization values $>60 \%$ may be considered borderline, these values are quite common for different Aeromonas species (Nhung et al., 2007; Alperi et al., 2010). This also happens among species of the neighbouring genus Vibrio (Gómez-Gil et al., 2003; Thompson et al., 2003).

The G $+\mathrm{C}$ content of the DNA of strains $\mathrm{A} 2-50^{\mathrm{T}}$ and $\mathrm{A} 2$ $67^{\mathrm{T}}$ was determined by three independent analyses by the HPLC technique at the BCCM/LMG Identification Service (Universiteit Gent, Belgium) following the procedures described by Miñana-Galbis et al. (2004, 2007). The DNA $\mathrm{G}+\mathrm{C}$ content of strains $\mathrm{A} 2-50^{\mathrm{T}}$ and $\mathrm{A} 2-67^{\mathrm{T}}$ was 62.8 and $63.1 \mathrm{~mol} \%$, respectively, within the range described for the genus Aeromonas (57-63 mol\%; Martin-Carnahan \& Joseph, 2005).

In order to determine colony characteristics, i.e. size, colour and production of brown diffusible pigment, strains $\mathrm{A} 2-50^{\mathrm{T}}$ and $\mathrm{A} 2-67^{\mathrm{T}}$ were grown at $30{ }^{\circ} \mathrm{C}$ for $24 \mathrm{~h}$ on TSA and on blood agar to determine the existence of haemolysis. Optimal growth temperature and $\mathrm{pH}$ were determined on TSB after $24 \mathrm{~h}$ by following optical density. Twenty-eight phenotypic tests, selected from Abbott et al. (2003) and listed in a previous study (Alperi et al., 2010), were used for the characterization of strains $\mathrm{A} 2-50^{\mathrm{T}}$ and $\mathrm{A} 2-67^{\mathrm{T}}$. These tests were performed three times and were incubated at $30{ }^{\circ} \mathrm{C}$ and also at $36{ }^{\circ} \mathrm{C}$, due to the clinical origin of the strains. Test results were read every $24 \mathrm{~h}$ for up to 7 days. Some tests were confirmed in parallel using commercial identification kits (API 20NE and API 20E; bioMérieux). Additional tests from the latter kits, together with acid production from/hydrolysis of 49 carbohydrates using API 50CH (bioMérieux), were also considered. The type strains of all Aeromonas species were evaluated, under conditions identical to those used for $\mathrm{A} 2-50^{\mathrm{T}}$ and $\mathrm{A} 2-67^{\mathrm{T}}$, for all differential tests included in Table 1.

Strains $A 2-50^{\mathrm{T}}$ and $\mathrm{A} 2-67^{\mathrm{T}}$ showed relatively similar biochemical profiles, but they could be differentiated from each other because $\mathrm{A} 2-50^{\mathrm{T}}$ was able to use citrate and to produce acid from raffinose, whereas strain $\mathrm{A} 2-67^{\mathrm{T}}$ was not. In addition, the latter was able to grow at $45{ }^{\circ} \mathrm{C}$ on sheep-blood agar, whereas strain $\mathrm{A} 2-50^{\mathrm{T}}$ was not (Table 1). No differences were observed between biochemical profiles at 30 and $36{ }^{\circ} \mathrm{C}$. Strains $\mathrm{A} 2-50^{\mathrm{T}}$ and $\mathrm{A} 2-67^{\mathrm{T}}$ showed distinctive characters that separated them from other species (A. hydrophila, A. veronii bv. Sobria and A. caviae) 
Table 1. Key tests for phenotypic differentiation of strains $A 2-50^{\top}$ (A. taiwanensis sp. nov.) and $A 2-67^{\top}$ (A. sanarellii sp. nov.) from other Aeromonas species

Taxa: A, A. taiwanensis sp. nov. (A2-50 $)$; B, A. sanarellii sp. nov. (A2-67 $\left.{ }^{\mathrm{T}}\right) ; 1$, A. hydrophila; 2, A. bestiarum; 3, A. salmonicida; 4, A. caviae; 5 , A. media; 6, A. eucrenophila; 7, A. sobria; 8, A. veroni bv. Sobria; 9, A. jandaei; 10, A. veronii bv. Veronii; 11, A. schubertii; 12, A. trota; 13, A. encheleia; 14, A. allosaccharophila; 15, A. popoffii; 16, A. simiae (tested at $30{ }^{\circ} \mathrm{C}$; data from Harf-Monteil et al., 2004); 17, A. molluscorum (Miñana-Galbis et al., 2007); 18, A. bivalvium (tested at $25-30{ }^{\circ} \mathrm{C}$; Miñana-Galbis et al., 2004); 19, A. aquariorum (tested at $30{ }^{\circ} \mathrm{C}$; Martínez-Murcia et al., 2008); 20, A. tecta (tested at $30{ }^{\circ} \mathrm{C}$; Demarta et al., 2008); 21 , A. fluvialis (tested at $30{ }^{\circ} \mathrm{C}$; Alperi et al., 2010). +, $85-100 \%$ of strains positive; $\mathrm{v}, 16-84 \%$ of strains positive; -, $0-15 \%$ of strains positive (results obtained in this study for type strains are given in parentheses). Data in columns 1-15 were obtained from Abbott et al. (2003), who performed tests at $35^{\circ} \mathrm{C}$, with the exception of $A$. popoffii and $A$. sobria, which were tested at $25{ }^{\circ} \mathrm{C}$, as did Miñana-Galbis et al. (2007). Tests carried out in this study for type strains as well as for the novel strains were performed at 36 and $30{ }^{\circ} \mathrm{C}$, with the exception of A. salmonicida, which was also tested at room temperature. Test results were read every $24 \mathrm{~h}$ for up to 7 days. ND, No data available from the cited study; VP, Voges-Proskauer reaction; LDH, lysine decarboxylase.

\begin{tabular}{|c|c|c|c|c|c|c|c|c|c|c|c|c|c|c|c|c|c|c|c|c|c|c|c|}
\hline Characteristic & A & B & 1 & 2 & 3 & 4 & 5 & 6 & 7 & 8 & 9 & 10 & 11 & 12 & 13 & 14 & 15 & 16 & 17 & 18 & 19 & 20 & 21 \\
\hline VP & - & - & $+(+)$ & $\mathrm{v}(+)$ & $\mathrm{v}(-)$ & $-(-)$ & $-(-)$ & $-(-)$ & $-(-)$ & $+(+)$ & $+(+)$ & $\mathrm{v}(-)$ & $\mathrm{V}(-)$ & $-(-)$ & $-(-)$ & $-(-)$ & $+(+)$ & $-(-)$ & $-(-)$ & $-(-)$ & $-(-)$ & $\mathrm{v}(+)$ & $-(-)$ \\
\hline LDH & - & - & $+(+)$ & $\mathrm{v}(-)$ & $\mathrm{v}(+)$ & $-(-)$ & $-(-)$ & $-(-)$ & $+(+)$ & $+(+)$ & $+(+)$ & $+(+)$ & $\mathrm{v}(-)$ & $+(+)$ & $-(-)$ & $+(+)$ & $-(-)$ & $+(+)$ & $-(-)$ & $+(+)$ & $+(+)$ & $\mathrm{v}(+)$ & $-(-)$ \\
\hline $\begin{array}{l}\text { Gas from } \\
\text { glucose }\end{array}$ & - & - & $+(+)$ & $\mathrm{v}(+)$ & $\mathrm{v}(-)$ & $-(-)$ & $-(-)$ & $\mathrm{v}(+)$ & $\mathrm{v}(+)$ & $+(+)$ & $+(+)$ & $+(+)$ & $-(-)$ & $\mathrm{v}(+)$ & $\mathrm{v}(+)$ & $+(+)$ & $+(+)$ & $-(-)$ & $-(-)$ & $-(-)$ & $+(+)$ & $+(+)$ & $+(+)$ \\
\hline $\begin{array}{l}\text { Hydrolysis of } \\
\text { aesculin }\end{array}$ & + & + & $+(+)$ & $\mathrm{v}(+)$ & $+(+)$ & $\mathrm{v}(+)$ & $\mathrm{v}(+)$ & $\mathrm{v}(+)$ & $-(-)$ & $-(-)$ & $-(-)$ & $+(+)$ & $-(-)$ & $-(-)$ & $\mathrm{v}(+)$ & $\mathrm{v}(+)$ & $-(-)$ & $\mathrm{v}(-)$ & $+(+)$ & $+(+)$ & $+(+)$ & $\mathrm{v}(-)$ & $-(-)$ \\
\hline $\begin{array}{l}\text { Citrate } \\
\text { utilization }\end{array}$ & + & - & $+(+)$ & $-(-)$ & $+(-)$ & $+(+)$ & $\mathrm{v}(+)$ & $-(-)$ & $+(+)$ & $\mathrm{v}(-)$ & $+(+)$ & $+(+)$ & $\mathrm{v}(+)$ & $+(+)$ & $-(-)$ & $\mathrm{v}(-)$ & $+(+)$ & $\mathrm{ND}(-)$ & $+(+)$ & $+(+)$ & $\mathrm{ND}(+)$ & $\mathrm{v}(+)$ & $+(+)$ \\
\hline $\begin{array}{l}\text { Growth at } 45{ }^{\circ} \mathrm{C} \\
\text { on sheep- } \\
\text { blood agar }\end{array}$ & - & + & $+(+)$ & $-(-)$ & $-(-)$ & $+(+)$ & $-(-)$ & $-(-)$ & $-(+)$ & $-(-)$ & $+(+)$ & $+(+)$ & $+(+)$ & $-(-)$ & $-(-)$ & $-(-)$ & $-(-)$ & $\mathrm{ND}(+)$ & $-(-)$ & $-(-)$ & $\mathrm{ND}(-)$ & $-(-)$ & $-(-)$ \\
\hline \multicolumn{24}{|l|}{ Acid from: } \\
\hline Amygdalin & + & + & $-(-)$ & $-(-)$ & $-(-)$ & $-(-)$ & $-(-)$ & $-(-)$ & $-(-)$ & $-(-)$ & $-(-)$ & $-(-)$ & $-(-)$ & $-(-)$ & $-(-)$ & $-(-)$ & $-(-)$ & $-(-)$ & $\mathrm{ND}(-)$ & $\mathrm{ND}(-)$ & $-(-)$ & $\mathrm{ND}(-)$ & $-(-)$ \\
\hline Cellobiose & - & - & $-(-)$ & $\mathrm{v}(-)$ & $\mathrm{v}(-)$ & $+(+)$ & $+(+)$ & $\mathrm{v}(+)$ & $+(+)$ & $\mathrm{v}(-)$ & $-(-)$ & $\mathrm{v}(+)$ & $-(-)$ & $+(+)$ & $-(-)$ & $+(+)$ & $-(-)$ & $+(+)$ & $\mathrm{v}(+)$ & $\mathrm{ND}(-)$ & $-(-)$ & $-(-)$ & $+(+)$ \\
\hline Raffinose & + & - & $-(-)$ & $-(-)$ & $-(-)$ & $-(-)$ & $-(-)$ & $-(-)$ & $-(-)$ & $-(-)$ & $-(-)$ & $-(-)$ & $-(-)$ & $-(-)$ & $-(-)$ & $\mathrm{v}(-)$ & $-(-)$ & $-(-)$ & $-(-)$ & $-(-)$ & $-(-)$ & $\mathrm{ND}(-)$ & $-(-)$ \\
\hline L-Arabinose & + & + & $\mathrm{v}(+)$ & $+(+)$ & $+(+)$ & $+(+)$ & $+(+)$ & $\mathrm{v}(+)$ & $-(-)$ & $-(+)$ & $-(-)$ & $-(-)$ & $-(-)$ & $-(-)$ & $-(-)$ & $\mathrm{v}(+)$ & $\mathrm{v}(+)$ & $-(-)$ & $+(+)$ & $+(+)$ & $-(-)$ & $-(-)$ & $-(-)$ \\
\hline Glycerol & + & + & $+(+)$ & $+(+)$ & $+(+)$ & $\mathrm{v}(-)$ & $\mathrm{v}(+)$ & $-(-)$ & $+(+)$ & $+(+)$ & $+(+)$ & $+(+)$ & $-(-)$ & $\mathrm{v}(+)$ & $+(+)$ & $+(+)$ & $+(+)$ & $+(+)$ & $+(+)$ & $+(+)$ & $+(+)$ & $+(+)$ & $+(+)$ \\
\hline D-Mannose & - & - & $+(+)$ & $+(+)$ & $+(-)$ & $\mathrm{v}(-)$ & $+(+)$ & $+(+)$ & $+(+)$ & $+(+)$ & $+(+)$ & $+(+)$ & $+(+)$ & $+(+)$ & $+(+)$ & $+(+)$ & $+(+)$ & $+(+)$ & $+(+)$ & $-(-)$ & $+(+)$ & $\mathrm{ND}(+)$ & $+(+)$ \\
\hline Salicin & + & + & $\mathrm{v}(-)$ & $\mathrm{v}(+)$ & $\mathrm{v}(-)$ & $\mathrm{v}(+)$ & $\mathrm{v}(+)$ & $\mathrm{v}(-)$ & $-(-)$ & $-(-)$ & $-(-)$ & $+(+)$ & $-(-)$ & $-(-)$ & $-(+)$ & $-(-)$ & $-(-)$ & $-(-)$ & $\mathrm{ND}(+)$ & $+(+)$ & $+(+)$ & $\mathrm{v}(-)$ & $+(+)$ \\
\hline
\end{tabular}


commonly encountered in clinical samples (Table 1). Interestingly, both strains were able to produce acid from amygdalin, a characteristic only described so far in nine Aeromonas strains within a study performed by Abbott et al. (2003), who evaluated the atypical phenotypic properties of the genus. In that study, they encountered four A. caviae strains that produced acid from amygdalin and from raffinose, which coincides with the profile of A2$50^{\mathrm{T}}$ (Table 1). Other traits that differentiated $\mathrm{A} 2-50^{\mathrm{T}}$ and A2 $-67^{\mathrm{T}}$ from other species were their capacity to produce acid from L-arabinose, glycerol and salicin as well as to hydrolyse aesculin, and their negative results for the Voges-Proskauer test, lysine decarboxylase activity and production of gas from glucose and acid from cellobiose and D-mannose (Table 1). Interestingly, strain A2-67 displayed two colony types of the same size $(4-5 \mathrm{~mm}$ in diameter). One was opaque, circular and beige in colour, while the other was translucent on TSA after $48 \mathrm{~h}$ at $30{ }^{\circ} \mathrm{C}$. These two morphologies were also observed on blood agar. The two colony types produced the same biochemical responses and showed identical ERIC-PCR profiles (not shown).

Cell sizes and morphologies and the presence of flagella were determined by electron microscopy following procedures described previously (Collado et al., 2009).

The susceptibilities of strains $\mathrm{A} 2-50^{\mathrm{T}}$ and $\mathrm{A} 2-67^{\mathrm{T}}$ against 27 antibiotics were tested, as described previously (Alperi et al., 2010). Both strains showed resistance to amoxicillin, amoxicillin plus clavulanic acid, ticarcillin, ticarcillin plus clavulanic acid, cephalothin and erythromycin; $\mathrm{A} 2-50^{\mathrm{T}}$ was intermediately susceptible to streptomycin, while $\mathrm{A} 2-67^{\mathrm{T}}$ showed resistance to cefoxitine. Both strains were susceptible to the other antimicrobials tested.

The 16S rRNA gene sequences, MLPA, phenotypic characterization and DNA-DNA reassociation results all clearly separated strain $\mathrm{A} 2-50^{\mathrm{T}}$ from $\mathrm{A} 2-67^{\mathrm{T}}$ and both strains from the other Aeromonas species.

\section{Description of Aeromonas taiwanensis sp. nov.}

Aeromonas taiwanensis (tai.wan.en'sis. N.L. masc. adj. taiwanensis of Taiwan, where the type strain was isolated).

Cells are straight, Gram-negative, non-spore-forming, nonencapsulated, motile rods, $0.8-1 \mu \mathrm{m}$ wide and $1.8-2.5 \mu \mathrm{m}$ long. Oxidase- and catalase-positive, reduces nitrate to nitrite and resistant to vibriostatic agent $\mathrm{O} / 129$. Colonies on TSA are $2-5 \mathrm{~mm}$ in diameter, opaque, circular and beige in colour after $48 \mathrm{~h}$ at $30{ }^{\circ} \mathrm{C}$. No brown diffusible pigment is produced on TSA. Optimal growth occurs at $30{ }^{\circ} \mathrm{C}$. Growth is observed at $36{ }^{\circ} \mathrm{C}$ but not at $\geqslant 40$ or $4{ }^{\circ} \mathrm{C}$ after $24 \mathrm{~h}$ on sheep-blood agar. No $\beta$-haemolysis is observed on sheep-blood agar at 30 or $36{ }^{\circ} \mathrm{C}$. Grows on MacConkey agar and in the absence of $\mathrm{NaCl}$ but not at $6 \%$ $\mathrm{NaCl}$ after $24 \mathrm{~h}$ on TSA. Optimal growth occurs at $\mathrm{pH} 8.5-$ 9.5 after $24 \mathrm{~h}$ on TSA; does not grow at $\mathrm{pH}$ 4.5. Produces indole from tryptophan and arginine dihydrolase activity, is positive for the ONPG test ( $\beta$-galactosidase activity) and hydrolysis of aesculin, gelatin, DNA and L-tryptophan and is able to use citrate. Negative for the Voges-Proskauer test, hydrolysis of elastin and urea, production of hydrogen sulfide from cysteine and gas from glucose, swarming and for lysine decarboxylase and ornithine decarboxylase tests. Hydrolyses starch, arbutin and aesculin. Uses D-glucose, L-arabinose, Dmannitol, maltose, $\mathrm{N}$-acetylglucosamine, potassium gluconate, capric acid, malic acid, glycogen and potassium gluconate as sole carbon and energy sources, but not potassium 2-ketogluconate, potassium 5-ketogluconate, Dmannose, adipic acid, phenylacetic acid or trisodium citrate. Acid is produced from D-glucose, sucrose, L-arabinose, raffinose, D-ribose, amygdalin, salicin, D-galactose, D-fructose, D-mannitol, glycerol, $N$-acetylglucosamine, maltose and trehalose, but not from cellobiose, D-arabinose, L-rhamnose, myo-inositol, erythritol, L- or D-xylose, D-adonitol, methyl $\beta$-D-xylopyranoside, D-mannose, L-sorbose, L-rhamnose, dulcitol, inositol, D-sorbitol, methyl $\alpha$-D-mannopyranoside, methyl $\alpha$-D-glucopyranoside, lactose, melibiose, inulin, melezitose, xylitol, gentiobiose, turanose, D-lyxose, D-tagatose, L- or D-fucose or L- or D-arabitol. The API $20 \mathrm{E}$ and API 20NE codes for the type strain are 3266127 and 7575754 , respectively. Resistant to amoxicillin, amoxicillin plus clavulanic acid, ticarcillin, ticarcillin plus clavulanic acid, cephalothin and erythromycin, shows intermediate resistance to streptomycin and is susceptible to piperacillin, piperacillin plus tazobactam, cefoxitine, cefotaxime, cefoperazone, ceftazidime, ceftriaxone, cefepime, aztreonam, imipenem, gentamicin, kanamycin, tobramycin, amikacin, tetracycline, ciprofloxacin, nalidixic acid, fosfomycin, trimethoprimsulfamethoxazole and chloramphenicol.

The type strain, A2-50 ${ }^{\mathrm{T}}\left(=\mathrm{CECT} 7403^{\mathrm{T}}=\mathrm{LMG} 24683^{\mathrm{T}}\right)$, was isolated from a wound infection from a patient at Tainan, Taiwan.

\section{Description of Aeromonas sanarellii sp. nov.}

Aeromonas sanarellii [sa.na.rell'i.i. N.L. gen. masc. n. sanarellii of Sanarelli, named in honour of G. Sanarelli, for his contribution to our knowledge of Aeromonas, having described the first member of Aeromonas as Bacillus hydrophilus fuscus in 1891 (Martin-Carnahan \& Joseph, 2005)].

Cells are straight, non-spore-forming, non-encapsulated, motile rods, $0.7 \mu \mathrm{m}$ wide and $2.5 \mu \mathrm{m}$ long. Gram-negative, oxidase- and catalase-positive, reduces nitrate to nitrite and resistant to vibriostatic agent O/129. Displays two colony types on TSA and blood agar. Colonies on TSA are 4$5 \mathrm{~mm}$ in diameter; one colony type is opaque, circular and beige in colour, while the other is translucent, after $48 \mathrm{~h}$ at $30{ }^{\circ} \mathrm{C}$. No brown diffusible pigment is produced on TSA. Optimal growth occurs at $30{ }^{\circ} \mathrm{C}$; growth is observed up to $45{ }^{\circ} \mathrm{C}$ but not at $50{ }^{\circ} \mathrm{C}$ after $48 \mathrm{~h}$ or at $4{ }^{\circ} \mathrm{C}$ after 7 days on sheep-blood agar. No $\beta$-haemolysis is observed on sheepblood agar at 30 or $36{ }^{\circ} \mathrm{C}$. Able to grow on MacConkey and in the absence of $\mathrm{NaCl}$ but not at $6 \% \mathrm{NaCl}$ on TSA. 
Optimal growth occurs at $\mathrm{pH} 9$ after $24 \mathrm{~h}$ on TSA; does not grow at $\mathrm{pH} 4.5$. Produces indole from tryptophan and arginine dihydrolase activity and is positive for the ONPG test ( $\beta$-galactosidase) and hydrolyses arbutin, starch, aesculin, gelatin, DNA and L-tryptophan. Negative for the Voges-Proskauer test, utilization of citrate, hydrolysis of elastin and urea, production of hydrogen sulfide from cysteine and gas from glucose, swarming and for lysine decarboxylase and ornithine decarboxylase tests. Able to use potassium gluconate, D-glucose, L-arabinose, D-mannitol, maltose, $\mathrm{N}$-acetylglucosamine, potassium gluconate, capric acid and malic acid as sole carbon and energy sources but not potassium 2-ketogluconate, potassium 5ketogluconate, D-mannose, adipic acid, phenylacetic acid or trisodium citrate. Acid is produced from D-glucose, sucrose, L-arabinose, D-ribose, amygdalin, salicin, Dgalactose, D-fructose, D-mannitol, glycerol, $\mathrm{N}$-acetylglucosamine, maltose, trehalose and glycogen but not from cellobiose, raffinose, D-arabinose, L-rhamnose, myo-inositol, erythritol, $\mathrm{L}^{-}$or $\mathrm{D}$-xylose, $\mathrm{D}$-adonitol, methyl $\beta$-Dxylopyranoside, D-mannose, L-sorbose, L-rhamnose, dulcitol, inositol, D-sorbitol, methyl $\alpha$-D-mannopyranoside, methyl $\alpha$-D-glucopyranoside, lactose, melibiose, inulin, melezitose, xylitol, gentiobiose, turanose, D-lyxose, Dtagatose, L- or D-fucose or L- or D- arabitol. The API 20E and API 20NE codes for the type strain are 3066127 and 7575754, respectively. Resistant to amoxicillin, amoxicillin plus clavulanic acid, ticarcillin, ticarcillin plus clavulanic acid, cephalothin, cefoxitine and erythromycin and susceptible to piperacillin, piperacillin plus tazobactam, cefotaxime, cefoperazone, ceftazidime, ceftriaxone, cefepime, aztreonam, imipenem, gentamicin, kanamycin, tobramycin, amikacin, streptomycin, tetracycline, ciprofloxacin, nalidixic acid, fosfomycin, trimethoprim-sulfamethoxazole and chloramphenicol.

The type strain, A2-67 $7^{\mathrm{T}}\left(=\mathrm{CECT} 7402^{\mathrm{T}}=\mathrm{LMG} 24682^{\mathrm{T}}\right)$, was isolated from a wound culture from a patient at Tainan, Taiwan.

\section{Acknowledgements}

We are grateful to $\mathrm{M}^{\mathrm{a}}$ Isabel Inza for her help in the phenotypic characterization and to Catalina Nuñez for her excellent technical assistance. We are also grateful to the Pharmacology Unit of the Rovira i Virgili University for the use of their Bio Whittaker KineticQCL Microplate Reader. MDC work has been partly supported by grant IMIDTA/2007/68 from IMPIVA, Generalitat Valenciana, Spain. Part of this work was also supported by funds from the European Commission for the HEALTHY WATER Project (FOOD-CT-2006036306). The authors are solely responsible for the content of this publication and it does not represent the opinion of the European Commission. The European Commission is not responsible for any use that might be made of data appearing therein.

\section{References}

Abbott, S. L., Cheung, W. K. \& Janda, J. M. (2003). The genus Aeromonas: biochemical characteristics, atypical reactions, and phenotypic identification schemes. J Clin Microbiol 41, 2348-2357.
Alperi, A., Figueras, M. J., Inza, I. \& Martínez-Murcia, A. J. (2008). Analysis of $16 \mathrm{~S}$ rRNA gene mutations in a subset of Aeromonas strains and their impact in species delineation. Int Microbiol 11, 185-194.

Alperi, A., Martínez-Murcia, A. J., Monera, A., Saavedra, M. J. \& Figueras, M. J. (2010). Aeromonas fluvialis sp. nov., isolated from a Spanish river. Int J Syst Evol Microbiol 60, 72-77.

Beaz-Hidalgo, R., Alperi, A., Figueras, M. J. \& Romalde, J. L. (2009). Aeromonas piscicola sp. nov., isolated from diseased fish. Syst Appl Microbiol 32, 471-479.

Borrell, N., Figueras, M. J. \& Guarro, J. (1998). Phenotypic identification of Aeromonas genomospecies from clinical and environmental sources. Can J Microbiol 44, 103-108.

Brosius, J., Palmer, M. L., Kennedy, P. J. \& Noller, H. F. (1978). Complete nucleotide sequence of a $16 \mathrm{~S}$ ribosomal RNA gene from Escherichia coli. Proc Natl Acad Sci U S A 75, 4801-4805.

Collado, L., Cleenwerck, I., Van Trappen, S., De Vos, P. \& Figueras, M. J. (2009). Arcobacter mytili sp. nov., an indoxyl acetate-hydrolysisnegative bacterium isolated from mussels. Int J Syst Evol Microbiol 59, 1391-1396.

Demarta, A., Küpfer, M., Riegel, P., Harf-Monteil, C., Tonolla, M., Peduzzi, R., Monera, A., Saavedra, M. J. \& Martínez-Murcia, A. J. (2008). Aeromonas tecta sp. nov., isolated from clinical and environmental sources. Syst Appl Microbiol 31, 278-286.

Figueras, M. J. (2005). Clinical relevance of Aeromonas sM503. Rev Med Microbiol 16, 145-153.

Figueras, M. J., Soler, L., Chacón, M. R., Guarro, J. \& MartínezMurcia, A. J. (2000). Extended method for discrimination of Aeromonas spp. by $16 \mathrm{~S}$ rDNA RFLP analysis. Int $J$ Syst Evol Microbiol 50, 2069-2073.

Figueras, M. J., Suarez-Franquet, A., Chacón, M. R., Soler, L., Navarro, M., Alejandre, C., Grasa, B., Martínez-Murcia, A. J. \& Guarro, J. (2005). First record of the rare species Aeromonas culicicola from a drinking water supply. Appl Environ Microbiol 71, 538-541.

Gómez-Gil, B., Thompson, F. L., Thompson, C. C. \& Swings, J. (2003). Vibrio rotiferianus sp. nov., isolated from cultures of the rotifer Brachionus plicatilis. Int J Syst Evol Microbiol 53, 239-243.

Harf-Monteil, C., Flèche, A. L., Riegel, P., Prévost, G., Bermond, D., Grimont, P. A. D. \& Monteil, H. (2004). Aeromonas simiae sp. nov., isolated from monkey faeces. Int J Syst Evol Microbiol 54, 481-485.

Huang, H. C., Yu, W. L., Huan, K. H., Cheng, K. C. \& Chuang, Y. C. (2007). Aeromonas sobria prostatitis and septic shock in a healthy man with chronic alcoholic consumption. Jpn J Infect Dis 60, 400-401.

Huys, G., Cnockaert, M. \& Swings, J. (2005). Aeromonas culicicola Pidiyar et al. 2002 is a later subjective synonym of Aeromonas veronii Hickman-Brenner et al. 1987. Syst Appl Microbiol 28, 604-609.

Kimura, M. (1980). A simple method for estimating evolutionary rates of base substitutions through comparative studies of nucleotide sequences. J Mol Evol 16, 111-120.

Küpfer, M., Kuhnert, P., Korczak, B. M., Peduzzi, R. \& Demarta, A. (2006). Genetic relationships of Aeromonas strains inferred from $16 \mathrm{~S}$ rRNA, gyrB and rpoB gene sequences. Int J Syst Evol Microbiol 56, 2743-2751.

Marmur, J. (1961). A procedure for the isolation of deoxyribonucleic acid from microorganisms. J Mol Biol 3, 208-218.

Martin-Carnahan, A. \& Joseph, S. W. (2005). Order XII. Aeromonadales ord. nov. In Bergey's Manual of Systematic Bacteriology, 2nd edn, vol. 2B, p. 556. Edited by D. J. Brenner, N. R. Krieg, J. T. Staley \& G. M. Garrity. New York: Springer.

Martínez-Murcia, A. J., Benlloch, S. \& Collins, M. D. (1992). Phylogenetic interrelationships of members of the genera Aeromonas and Plesiomonas as determined by $16 \mathrm{~S}$ ribosomal DNA 
sequencing: lack of congruence with results of DNA-DNA hybridizations. Int J Syst Bacteriol 42, 412-421.

Martínez-Murcia, A. J., Soler, L., Saavedra, M. J., Chacón, M. R., Guarro, J., Stackebrandt, E. \& Figueras, M. J. (2005). Phenotypic, genotypic, and phylogenetic discrepancies to differentiate Aeromonas salmonicida from Aeromonas bestiarum. Int Microbiol 8, 259-269.

Martínez-Murcia, A. J., Figueras, M. J., Saavedra, M. J. \& Stackebrandt, E. (2007). The recently proposed species Aeromonas sharmana sp. nov., isolate GPTSA- $6^{\mathrm{T}}$, is not a member of the genus Aeromonas. Int Microbiol 10, 61-64.

Martínez-Murcia, A. J., Saavedra, M. J., Mota, V. R., Maier, T., Stackebrandt, E. \& Cousin, S. (2008). Aeromonas aquariorum sp. nov., isolated from aquaria of ornamental fish. Int $J$ Syst Evol Microbiol 58, 1169-1175.

Martínez-Murcia, A. J., Monera, A., Alperi, A., Figueras, M. J. \& Saavedra, M. J. (2009). Phylogenetic evidence suggests that strains of Aeromonas hydrophila subsp. dhakensis belong to the species Aeromonas aquariorum sp. nov. Curr Microbiol 58, 76-80.

Miñana-Galbis, D., Farfán, M., Fusté, M. C. \& Lorén, J. G. (2004). Aeromonas molluscorum sp. nov., isolated from bivalve molluscs. Int $J$ Syst Evol Microbiol 54, 2073-2078.

Miñana-Galbis, D., Farfán, M., Fusté, M. C. \& Lorén, J. G. (2007). Aeromonas bivalvium sp. nov., isolated from bivalve molluscs. Int $J$ Syst Evol Microbiol 57, 582-587.

Morandi, A., Zhaxybayeva, O., Gogarten, J. P. \& Graf, J. (2005). Evolutionary and diagnostic implications of intragenomic heterogeneity in the 16S rRNA gene in Aeromonas strains. J Bacteriol 187, 65616564.

Nhung, P. H., Hata, H., Ohkusu, K., Noda, M., Shah, M. M., Goto, K. \& Ezaki, T. (2007). Use of the novel phylogenetic marker dnaJ and DNA-DNA hybridization to clarify interrelationships within the genus Aeromonas. Int J Syst Evol Microbiol 57, 1232-1237.

Ormen, O., Granum, P. E., Lassen, J. \& Figueras, M. J. (2005). Lack of agreement between biochemical and genetic identification of Aeromonas spp. APMIS 113, 203-207.

Rosselló-Móra, R. (2006). DNA-DNA reassociation applied to microbial taxonomy and their critical evaluation. In Molecular Identification, Systematics, and Population Structure of Prokaryotes, p. 105. Edited by E. Stackebrandt. Berlin \& Heidelberg: Springer.

Saavedra, M. J., Figueras, M. J. \& Martínez-Murcia, A. J. (2006). Updated phylogeny of the genus Aeromonas. Int J Syst Evol Microbiol 56, 2481-2487.

Saitou, N. \& Nei, M. (1987). The neighbor-joining method: a new method for reconstructing phylogenetic trees. Mol Biol Evol 4, 406425.

Sepe, A., Barbieri, P., Peduzzi, R. \& Demarta, A. (2008). Evaluation of recA sequencing for the classification of Aeromonas strains at the genotype level. Lett Appl Microbiol 46, 439-444.

Soler, L., Marco, F., Vila, J., Chacón, M. R., Guarro, J. \& Figueras, M. J. (2003). Evaluation of two miniaturized systems, MicroScan W/A and
BBL Crystal E/NF, for identification of clinical isolates of Aeromonas spp. J Clin Microbiol 41, 5732-5734.

Soler, L., Yañez, M. A., Chacón, M. R., Aguilera-Arreola, M. G., Catalán, V., Figueras, M. J. \& Martínez-Murcia, A. J. (2004). Phylogenetic analysis of the genus Aeromonas based on two housekeeping genes. Int J Syst Evol Microbiol 54, 1511-1519.

Stackebrandt, E. \& Ebers, J. (2006). Taxonomic parameters revisited: tarnished gold standards. Microbiol Today 33, 152-155.

Stackebrandt, E. \& Goebel, B. M. (1994). Taxonomic note: a place for DNA-DNA reassociation and $16 \mathrm{~S}$ rRNA sequence analysis in the present species definition in bacteriology. Int J Syst Bacteriol 44, 846849.

Stackebrandt, E., Frederiksen, W., Garrity, G. M., Grimont, P. A. D., Kämpfer, P., Maiden, M. C. J., Nesme, X., Rosselló-Mora, R., Swings, J. \& other authors (2002). Report of the ad hoc committee for the reevaluation of the species definition in bacteriology. Int J Syst Evol Microbiol 52, 1043-1047.

Tamura, K., Dudley, J., Nei, M. \& Kumar, S. (2007). MEGA4: molecular evolutionary genetics analysis (MEGA) software version 4.0. Mol Biol Evol 24, 1596-1599.

Thompson, J. D., Higgins, D. G. \& Gibson, T. J. (1994). CLUSTAL W: improving the sensitivity of progressive multiple sequence alignment through sequence weighting, position-specific gap penalties and weight matrix choice. Nucleic Acids Res 22, 4673-4680.

Thompson, F. L., Thompson, C. C., Li, Y., Gómez-Gil, B., Vandenberghe, J., Hoste, B. \& Swings, J. (2003). Vibrio kanaloae sp. nov., Vibrio pomeroyi sp. nov. and Vibrio chagasii sp. nov., from sea water and marine animals. Int J Syst Evol Microbiol 53, 753-759.

Urdiain, M., López-López, A., Gonzalo, C., Busse, H. J., Langer, S., Kämpfer, P. \& Rosselló-Móra, R. (2008). Reclassification of Rhodobium marinum and Rhodobium pfennigii as Afifella marina gen. nov. comb. nov. and Afifella pfennigii comb. nov., a new genus of photoheterotrophic Alphaproteobacteria and emended descriptions of Rhodobium, Rhodobium orientis and Rhodobium gokarnense. Syst Appl Microbiol 31, 339-351.

Wayne, L. G., Brenner, D. J., Colwell, R. R., Grimont, P. A. D., Kandler, O., Krichevsky, M. I., Moore, L. H., Moore, W. E. C., Murray, R. G. E. \& other authors (1987). International Committee on Systematic Bacteriology. Report of the ad hoc committee on reconciliation of approaches to bacterial systematics. Int J Syst Bacteriol 37, 463-464.

Wu, C. J., Wu, J. J., Yan, J. J., Lee, H. C., Lee, N. Y., Chang, C. M., Shih, H. I., Wu, H. M., Wang, L. R. \& Ko, W. C. (2007). Clinical significance and distribution of putative virulence markers of 116 consecutive clinical Aeromonas isolates in southern Taiwan. J Infect 54, 151-158.

Yañez, M. A., Catalán, V., Apraiz, D., Figueras, M. J. \& MartínezMurcia, A. J. (2003). Phylogenetic analysis of members of the genus Aeromonas based on gyrB gene sequences. Int J Syst Evol Microbiol 53, 875-883.

Ziemke, F., Höfle, M. G., Lalucat, J. \& Rosselló-Mora, R. (1998). Reclassification of Shewanella putrefaciens Owen's genomic group II as Shewanella baltica sp. nov. Int J Syst Bacteriol 48, 179-186. 